\title{
Research on pipeline and flow assurance solutions of oil and gas transportation from Diamond WHP to FPSO Ruby II
}

\author{
Thinh Van Nguyen ${ }^{1,}{ }^{*}$, Chinh Duc Nguyen ${ }^{2}$, Truong Hung Trieu ${ }^{1}$ \\ ${ }^{1}$ Hanoi University of Mining and Geology, Hanoi, Vietnam \\ 2 Petro Vietnam Exploration Production Corporation, Hanoi, Vietnam
}

\section{ARTICLE INFO ABSTRACT}

Article history:

Received 02 $2^{\text {nd }}$ Nov. 2020

Revised 23rd Feb. 2021

Accepted 23rd Mar. 2021

\section{Keywords:}

Diamond WHP,

Flow assurance,

Wax deposition.
In offshore production of oil and gas, transporting products by subsea pipeline always has potential risks affecting the efficiency of the transportation process. For the Diamond oilfield, the process of gathering products and transportation is carried out according to a closed scheme in which the exploited products are preliminarily treated. The separated oil is transported to FPSO Ruby - II while the separated gas passed through the air compressor to increase pressure and then used for gaslift production. In fact, the oil produced at the Diamond oilfield has a high paraffin content, which causes difficulties during transportation. Therefore, the study on flow assurance to ensure the transportation of oil and gas from the Diamond oilfield to the FPSO Ruby - II is imperative. This paper presents the results of the research on flow assurance to maintain the safety of the transportation basing on the analysis of field data and the capability of the current subsea pipeline in comparison with the data gained from models carried out with OLGA software. The results show that the rate of wax deposition at normal steady state condition is relatively low. In addition, the thickness of wax deposition build - up is relatively small by simulation results. However, due to low temperature of transported oil which is lower than pour point temperature, a freeze layer will form on the surface of the pipeline. Therefore, regular pigging is considered the most effective way to remove wax.

Copyright (C) 2021 Hanoi University of Mining and Geology. All rights reserved.

${ }^{*}$ Corresponding author

E - mail: nguyenvanthinh@humg.edu.vn

DOI: 10.46326/JMES.2021.62(2).07 


\title{
Nghiên cứu giải pháp đảm bảo dòng chảy cho tuyến ống vận chuyển hỗn hợp dầu khí từ giàn Diamond về tàu FPSO Ruby - II
}

\author{
Nguyễn Văn Thịnh ${ }^{1,}{ }^{*}$, Nguyễn Đức Chính ${ }^{2}$, Triệu Hùng Trường 1 \\ ${ }^{1}$ Trường Đại học Mỏ - Địa chất, Hà Nội, Việt Nam \\ 2 Tổng Công ty Thăm dò Khai thác Dầu khí, Hà Nội, Việt Nam
}

THÔNG TIN BÀI BÁO T TÓM TẮT

\section{Quá trình:}

Nhận bài 02/11/2020

Sửa xong 23/02/2021

Chap nhận đăng 23/3/2021

Tù̀ khóa:

Bảo đảm dòng chảy,

Giàn Diamond,

Lắng đọng Wax.
Trong hoạt động khai thác dầu khí trên biển, vận chuyển sản phẩm bằng đường ống ngầm luôn tiềm ẩn nhũng nguy cơ gầy ảnh hưởng đến hiệu quả của quá trình vận chuyển. Đối với mỏ dầu khí Diamond, quá trình thu gom và vận chuyển sản phẩm được thực hiện theo so đồ thu gom kín, tức là sản phẩm khai thác được xử lý tách pha sơ bộ. Dầu sau khi tách khí sơ bộ được vận chyển ra tàu chứa FPSO Ruby - II. Khí sau khi tách được đưa qua máy nén khí để tăng áp suất và sử dụng cho hoạt động khai thác gaslift của mỏ. Thực tếcho thấy, dầu được khai thác tại mỏ Diamond có hàm lượng paraffin cao. Do vậy, khi vận chuyển loại dầu này thường kèm theo nhũng phức tạp nảy sinh, gây ảnh hưởng đến hiệu quả của quá trình vận chuyển. Do vậy, cần phải có các nghiên cúu về đảm bảo chế độ dòng chảy để vận chuyển dầu an toàn tù̀ mỏ Diamond ra tàu chúra FPSO Ruy - II. Bài báo trình bày các kết quả nghiên cúu để đảm bảo quá trình vận chuyển sản phẩm được an toàn, hiệu quả thông qua việc phân tích các số liệu thực tế và hiệu quả làm việc của đường ống hiện thời tại mỏ và các số liệu thu được tù mô hình hóa dựa trên phần mềm chuyên dựng OLGA. Kết quả nghiên cúu chỉ ra rằng, tỷ lê hình thành wax ở điều kiện ổn định bình thường là tưong đối thấp. Độ dày của lớp wax được tạo ra là tương đối nhỏ theo kết quả mô phỏng. Tuy nhiên, do nhiệt độ dầu vận chuyển thấp hơn nhiệt độ đông đặc, do đó một lớp wax sẽ hình thành và bám lên bề mặt của đường ống.

\section{Tổng quan về mỏ Diamond và đặc tính chất lưu}

Mỏ Diamond thuộc Lô 01\&02, nằm cách mỏ Ruby gần 18 km về phía bắc và cách cảng Vũng

"Tác giả liên hệ

E-mail: nguyenvanthinh@humg.edu.vn DOI: 10.46326/JMES.2021.62(2).07
Tàu 155 km về phía đông, độ sâu nước biển là 41,8 m (Hình 1). Hiện nay, tại mỏ Diamond đang khai thác các giếng $1 \mathrm{PS}, 1 \mathrm{PL}, 2 \mathrm{PS}, 2 \mathrm{PL}, 3 \mathrm{P}, 4 \mathrm{P}$ và $5 \mathrm{P}$. Sản phẩm khai thác tại mỏ Diamond được xử lý qua thiết bị tách pha sơ bộ để tách thành 2 pha riêng biệt (pha khí và pha lỏng). Dầu sau khi tách khí sơ bộ được vận chuyển ra tàu chứa FPSO Ruby - II thông qua đường ống ngầm dưới đáy biển với chiều dài $18 \mathrm{~km}$. Khí sau khi tách được đưa qua 
máy nén khí để tăng áp suất và sử dụng cho hoạt động khai thác gaslift, phần khí dư sẽ được chuyển sang tàu FPSO Ruby - II. Về cơ bản, dầu được khai thác tại mỏ Diamond có hàm lượng paraffin cao và thay đổi trong phạm vi rộng $(19 \div 27 \%)$. Nhìn chung, khi vận chuyển loại dầu này thường kèm theo những phức tạp nảy sinh, gây ảnh hưởng đến hiệu quả của quá trình vận chuyển (Từ Thành Nghĩa và nnk., 2015; Phung Dinh Thuc và nnk., 2003). Do đó, vấn đề bảo đảm dòng chảy là nội dung nghiên cứu quan trọng giúp cho quá trình vận chuyển được an toàn (Ove Bratland, 2013). Kết quả phân tích dầu tại mỏ Diamond cho thấy, nhiệt độ nóng chảy của paraffin thay đổi $55 \div 61^{\circ} \mathrm{C}$. Nhiệt độ bão hòa paraffin của dầu ở áp suất vỉa thay đổi $49 \div 56^{\circ} \mathrm{C}$, ở áp suất khí quyển giá trị này nằm trong khoảng $55 \div 60^{\circ} \mathrm{C}$, nhiệt độ đông đặc của dầu là $32 \div 36^{\circ} \mathrm{C}$. Kết quả nghiên cứu cho thấy, dầu tại mỏ Diamond thuộc loại dầu nặng, hàm lượng paraffin và nhiệt độ đông đặc cao. Nhiều nghiên cứu cho thấy, vận chuyển dầu có hàm lượng paraffin và nhiệt độ đông đặc cao thường gây ra các yếu tố gây bất lợi cho quá trình vận chuyển bằng đường ống ngầm, làm tăng quá trình hình thành wax bám dính trên thành ống (Hyun Su Lee, 2008; Aiyejna và nnk., 2011; Burger và nnk., 1981).Dựa trên các số liệu nghiên cứu về dầu thô tại mỏ Diamond (PVEP, 2018; 2019), đặc tích cơ bản của dầu Diamon được tổng hợp trong các Bảng $1 \div 3$. Các đặc tính wax của mẫu hỗn hợp dầu Diamond được trình bày trong Bảng 4 .

\section{Bảng 1. Đặc tính cơ bản của dầu tách khí tại mỏ Diamond.}

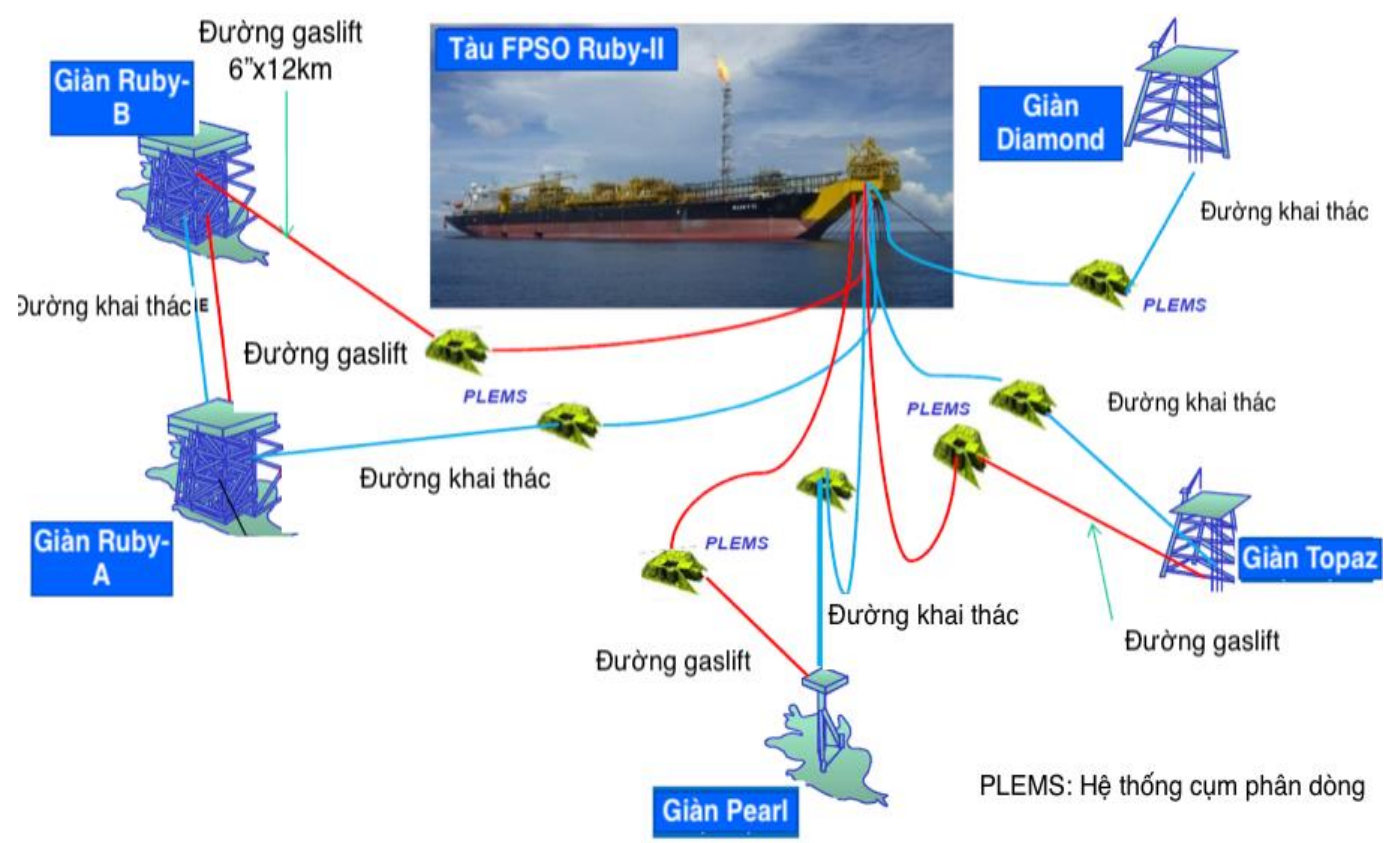

Hình 1. Sơ đồ vận chuyển sản phẩm tại mỏ Ruby.

\begin{tabular}{|l|l|l|}
\hline \multicolumn{1}{|c|}{ Thông số kiểm tra } & \multicolumn{1}{|c|}{ Đơn vị } & \multicolumn{1}{c|}{ Giá trị } \\
\hline Nhiệt độ đông đặc & ${ }^{0} \mathrm{C}$ & 36 \\
\hline Khối lượng riêng & $\mathrm{g} / \mathrm{ml}$ & 0,8557 \\
\hline Tỷ trọng API & API & 33,78 \\
\hline Tổng độ axit & $\mathrm{mgKOH} / \mathrm{g}$ & 0,408 \\
\hline
\end{tabular}


Bảng 2. Thành phần của hỗn hợp dầu tại Diamond.

\begin{tabular}{|c|c|c|}
\hline \multicolumn{3}{|c|}{ Mẫu dầu tách khí từ giàn Diamond } \\
\hline Thành phần & Hàm lượng Mol (\%) & Trọng lượng (\%) \\
\hline Methane & 0,000 & 0,000 \\
\hline Ethane & 0,000 & 0,000 \\
\hline Propane & 0,013 & 0,002 \\
\hline i-Butane & 0,022 & 0,005 \\
\hline n-Butane & 0,071 & 0,016 \\
\hline neo-Pentane & 0,005 & 0,002 \\
\hline i-Pentane & 0,165 & 0,046 \\
\hline n-Pentane & 0,270 & 0,076 \\
\hline Hexanes & 1,363 & 0,457 \\
\hline Me-Cyclo-pentane & 0,475 & 0,155 \\
\hline Benzene & 0,181 & 0,055 \\
\hline Cyclo-hexane & 0,534 & 0,175 \\
\hline Heptanes & 2,968 & 1,156 \\
\hline Me-Cyclo-hexane & 1,866 & 0,712 \\
\hline Toluene & 0,650 & 0,233 \\
\hline Octanes & 5,903 & 2,621 \\
\hline Ethyl-benzene & 0,221 & 0,091 \\
\hline Meta/Para-xylene & 1,133 & 0,467 \\
\hline Ortho-xylene & 0,448 & 0,185 \\
\hline Nonanes & 5,949 & 2,965 \\
\hline 1,2,4-Tri-Me-benzene & 0,559 & 0,261 \\
\hline Decanes & 5,647 & 3,123 \\
\hline Undecanes & 5,550 & 3,171 \\
\hline Dodecanes & 4,898 & 3,065 \\
\hline Tridecanes & 5,290 & 3,598 \\
\hline Tetradecanes & 4,316 & 3,187 \\
\hline Pentadecanes & 5,234 & 4,190 \\
\hline Hexadecanes & 3,181 & 2,745 \\
\hline Heptadecanes & 2,798 & 2,577 \\
\hline Octadecanes & 3,902 & 3,807 \\
\hline Nonadecanes & 2,774 & 2,835 \\
\hline Eicosanes & 2,331 & 2,491 \\
\hline Heneicosanes & 2,176 & 2,461 \\
\hline Docosanes & 2,071 & 2,455 \\
\hline Tricosanes & 2,106 & 2,603 \\
\hline Tetracosanes & 1,815 & 2,334 \\
\hline Pentacosanes & 1,799 & 2,412 \\
\hline Hexacosanes & 1,838 & 2,564 \\
\hline Heptacosanes & 1,800 & 2,616 \\
\hline Octacosanes & 1,733 & 2,613 \\
\hline Nonacosanes & 1,689 & 2,638 \\
\hline Triacontanes & 1,378 & 2,228 \\
\hline Hentriacontanes & 1,117 & 1,867 \\
\hline Dotriacontanes & 0,980 & 1,692 \\
\hline Tritriacontanes & 0,896 & 1,595 \\
\hline Tetratriacontanes & 0,736 & 1,349 \\
\hline Pentatriacontanes & 0,682 & 1,288 \\
\hline Hexatriacontanes plus & 8,465 & 22,814 \\
\hline Tổng: & 100,000 & 100,000 \\
\hline \multicolumn{2}{|c|}{$\mathrm{C}_{36+}$ Trọng lượng phân tử (g/mol) } & 693 \\
\hline \multicolumn{2}{|c|}{$\mathrm{C}_{36+} \mathrm{T}$ Trọng lượng riêng ở $60^{\circ} \mathrm{F}\left(\mathrm{g} / \mathrm{cm}^{3}\right)$} & 0.9445 \\
\hline
\end{tabular}


Bảng 3. Thành phần của hỗn hợp khí tại Diamond.

\begin{tabular}{|l|l|l|l|}
\hline Loại mẫu & Tách áp suất cao & Tách áp suất thấp & Hỗn Hợp khí \\
\hline Thành phần & Mol (\%) & Mol (\%) & Mol (\%) \\
\hline Methane & 80,9414 & 63,6135 & 78,8901 \\
\hline Ethane & 9,7609 & 10,6565 & 9,9478 \\
\hline Propane & 4,8226 & 11,1438 & 5,5393 \\
\hline Iso - Butane & 0,9999 & 2,5718 & 1,1758 \\
\hline N - Butane & 1,4381 & 4,3446 & 1,7344 \\
\hline Neo - Pentane & 0,0061 & 0,0106 & 0,0066 \\
\hline Iso - Pentane & 0,3893 & 1,3219 & 0,4858 \\
\hline N - Pentane & 0,3696 & 1,3127 & 0,4644 \\
\hline Hexanes & 0,2958 & 1,1149 & 0,3876 \\
\hline Heptanes & 0,2709 & 1,0825 & 0,3602 \\
\hline Octanes & 0,2293 & 0,8616 & 0,2695 \\
\hline Nonanes & 0,0905 & 0,3543 & 0,0983 \\
\hline C10 & 0,0338 & 0,14 & 0,0889 \\
\hline C11 & 0,0088 & 0,0208 & 0,0648 \\
\hline C12+ & 0,0045 & 0,0013 & 0,0082 \\
\hline Nitrogen & 0,204 & 0,4064 & 0,2331 \\
\hline CO 2 & 0,1346 & 1,0428 & 0,2455 \\
\hline C7+ MW & 112,7 & 112,1 & 116,5 \\
\hline C7+ density & 0,7034 & 0,7028 & 0,7073 \\
\hline
\end{tabular}

Bảng 4. Đặc tính wax của hốn hợp dầu tại mỏ Diamond.

\begin{tabular}{|l|c|c|}
\hline \multicolumn{1}{|c|}{ Thông số kiểm tra } & Đơn vị & Giá trị \\
\hline Hàm lượng Wax & $\%$ KL & 19,82 \\
\hline Nhiệt độ xuất hiện Wax & ${ }^{\circ} \mathrm{C}$ & 59,27 \\
\hline Nhiệt độ hòa tan Wax & ${ }^{\circ} \mathrm{C}$ & 69,78 \\
\hline Hàm lượng Asphaltene & $\%$ KL & 0,25 \\
\hline
\end{tabular}

Bảng 5. Các thông số của đường ống

\begin{tabular}{|l|c|c|}
\hline \multicolumn{1}{|c|}{ Thông số } & Đơn vị & Giá trị \\
\hline Chiều dài & $\mathrm{Km}$ & 17,875 \\
\hline Độ dày & $\mathrm{mm}$ & 10 \\
\hline Đường kính trong & $\mathrm{mm}$ & 253 \\
\hline Độ nhám ống & $\mathrm{mm}$ & 0,05 \\
\hline Vật liệu làm ống & - & $\begin{array}{c}\text { Carbon Steel - } \\
\text { ISO 3183 }\end{array}$ \\
\hline $\begin{array}{l}\text { Độ dẫn nhiệt của đường } \\
\text { ống }\end{array}$ & $\mathrm{W} / \mathrm{m} . \mathrm{K}$ & 54 \\
\hline Độ dày bê tông & $\mathrm{mm}$ & 55 \\
\hline Độ dẫn nhiệt của bê tông & $\mathrm{W} / \mathrm{m} . \mathrm{K}$ & 1,8 \\
\hline
\end{tabular}

2. Mô hình hóa và đề xuất giải pháp đảm bảo chế độ dòng chảy cho tuyến ống vận chuyển hỗn hợp dầu khí từ giàn Diamond về tàu FPSO Ruby-II
Bảng 6. Dữ liệu đoạn ống đứng nối lên tàu FPSO Ruby- II.

\begin{tabular}{|l|c|c|}
\hline \multicolumn{1}{|c|}{ Thông số } & Đơn vị & Giá trị \\
\hline Đường kính ngoài & $\mathrm{mm}$ & 273 \\
\hline Độ dày & $\mathrm{mm}$ & 10 \\
\hline Đường kính trong & $\mathrm{mm}$ & 253 \\
\hline Độ nhám & $\mathrm{mm}$ & 0,05 \\
\hline Độ dày lớp vỏ FBE & $\mathrm{mm}$ & 0,5 \\
\hline Độ dày lớp vỏ Neoprene & $\mathrm{mm}$ & 12,7 \\
\hline Độ dẫn nhiệt FBE & $\mathrm{W} / \mathrm{m} . \mathrm{K}$ & 0,26 \\
\hline Độ dẫn nhiệt Neoprene & $\mathrm{W} / \mathrm{m} . \mathrm{K}$ & 0,24 \\
\hline
\end{tabular}

Tuyến ống vận chuyển sản phẩm từ giàn Diamond về tàu FPSO Ruby - II có tổng chiều dài $18 \mathrm{~km}$ được đặt trên nền cát của đáy biển, chiều sâu của nước biển khu vực này trung bình 41,8 m. 


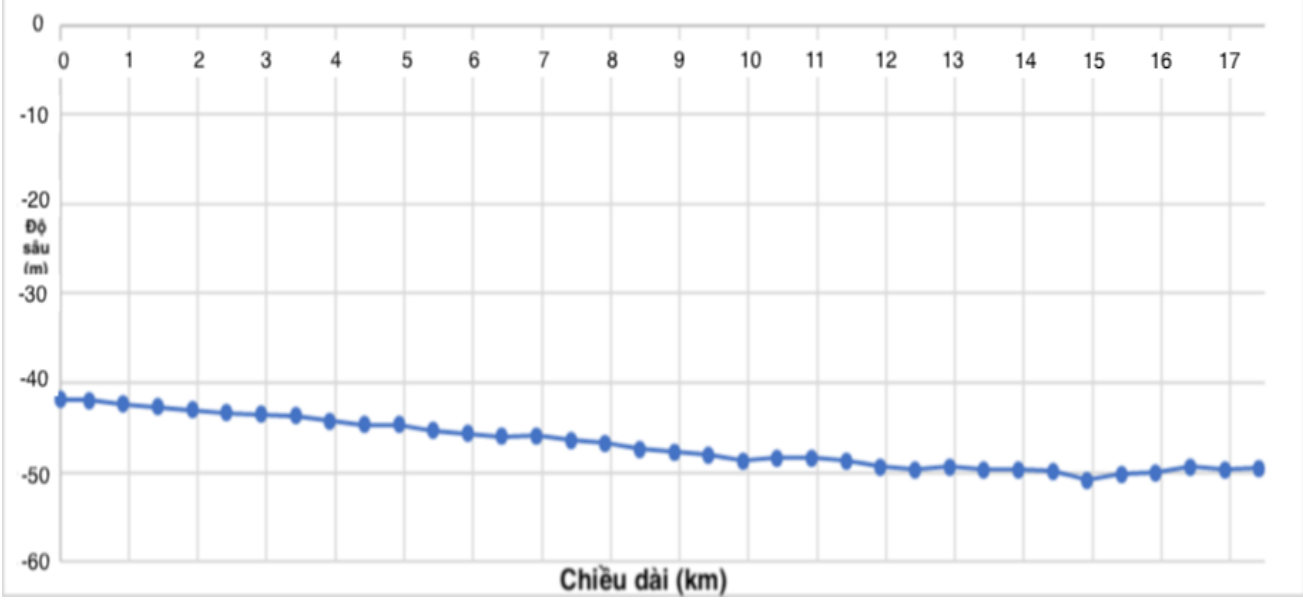

Hình 2. Hình dạng tuyến ống tù giàn Diamond về tàu FPSO Ruby - II.(đoạn dưới đáy biển).

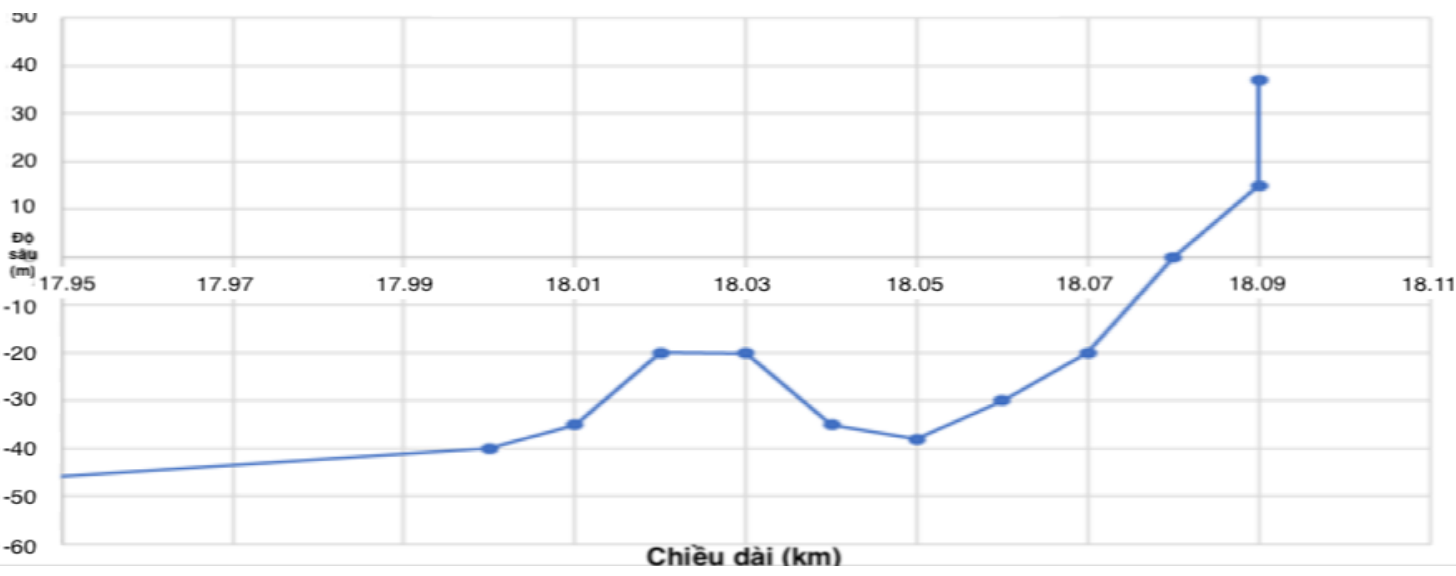

Hình 3. Hình dạng tuyến ống đứng nối lên tàu FPSO Ruby - II. (đoạn từ đáy biển nối lên tàu).

Trên cơ sở các số liệu khảo sát địa hình tuyến đường ống từ giàn Diamond về tàu FPSO Ruby - II, mặt cắt dọc tuyến ống nằm dưới mặt biển có dạng như Hình 2 và đoạn ống đứng lên tàu FPSO Ruby II có dạng như Hình 3.

\subsection{Các thông số của tuyến ống}

Các thông số của tuyến ống được trình bày trong các Bảng 5 và 6 dưới đây

Dựa trên biểu đồ dự đoán khai thác của mỏ, nhóm tác giả sử dụng phần mềm OLGA để nghiên cứu đảm bảo dòng chảy cho 03 trường hợp với các thông số về lưu lượng được thể hiện trong Bảng 7.

- Xác định trạng thái ổn định của dòng chảy

Kết quả mô hình hóa về trạng thái ổn định lượng chất lỏng ở FPSO Ruby-II cho thấy, mức độ dao động chủ yếu tập trung vào trường hợp 1, 2 . Trường hợp khai thác với kịch bản lượng dầu khai thác thấp nhất và không có khí (trường hợp 3), mức độ dao động của chất lỏng hầu như không xảy ra (Hình 4). Tương tự đối với sự biến thiên của tổng lượng chất lỏng trong đường ống cho các trường hợp nghiên cứu thể hiện trong Hình 5.

Do dòng chảy không ổn định, nên lượng chất lỏng cũng không được ổn định đối với trường hợp nghiên cứu. Chất lỏng tồn đọng trong đường ống cho các trường hợp nghiên cứu được thể hiện ở Hình 6, chúng phụ thuộc vào tỷ số khí dầu (GOR).

- Xác định độ biến thiên áp suất

Hình 7 thể hiện kết quả mô hình hóa của sự biến thiên thông số áp suất tại vị trí ống đứng nối lên tàu FPSO trong thời gian 24 giờ cho 3 trường hợp nghiên cứu. Có thể thấy, mức độ dao động áp suất lớn nhất xảy ra đối với trường hợp 2 , nguyên nhân là do lượng khí trong trường hợp này lớn hơn so với các trường hợp còn lại. 
Nguyễn Văn Thịnh và nnk/Tạp chí Khoa học Kỹ thuật Mỏ - Địa chất 62 (2), 65 - 78

Bảng 7. Các trường hợp nghiên cứu bảo đảm dòng chảy.

\begin{tabular}{|c|c|c|c|c|c|c|c|c|}
\hline $\begin{array}{c}\text { Trường } \\
\text { hợp }\end{array}$ & $\begin{array}{c}\text { Kịch bản khai } \\
\text { thác }\end{array}$ & Năm & $\begin{array}{c}\text { Lưu lượng } \\
\text { dầu, } \\
\text { (stb/d) }\end{array}$ & $\begin{array}{c}\text { Lưu lượng } \\
\text { nước, } \\
\text { (stb/d) }\end{array}$ & $\begin{array}{c}\text { Lưu lượng } \\
\text { chất lỏng, } \\
\text { (stb/d) }\end{array}$ & $\begin{array}{c}\text { Hàm lượng } \\
\text { nước, (\%) }\end{array}$ & $\begin{array}{c}\text { Lư lượng } \\
\text { khí, } \\
\text { (MMscf/d) }\end{array}$ & $\begin{array}{c}\text { Tỷ số khí } \\
\text { dầu, } \\
\text { (scf/stb) }\end{array}$ \\
\hline 1 & Tối đa & 2020 & 2.260 & 4.097 & 6.357 & 645 & 279 & 909 \\
\hline 2 & Trung bình & 2023 & 771 & 3.970 & 4.741 & 837 & 2.538 & 1.346 \\
\hline 3 & $\begin{array}{c}\text { Thấp nhất/ } \\
\text { không có khí }\end{array}$ & 2026 & 313 & 1.808 & 2.122 & 852 & 1.425 & - \\
\hline
\end{tabular}

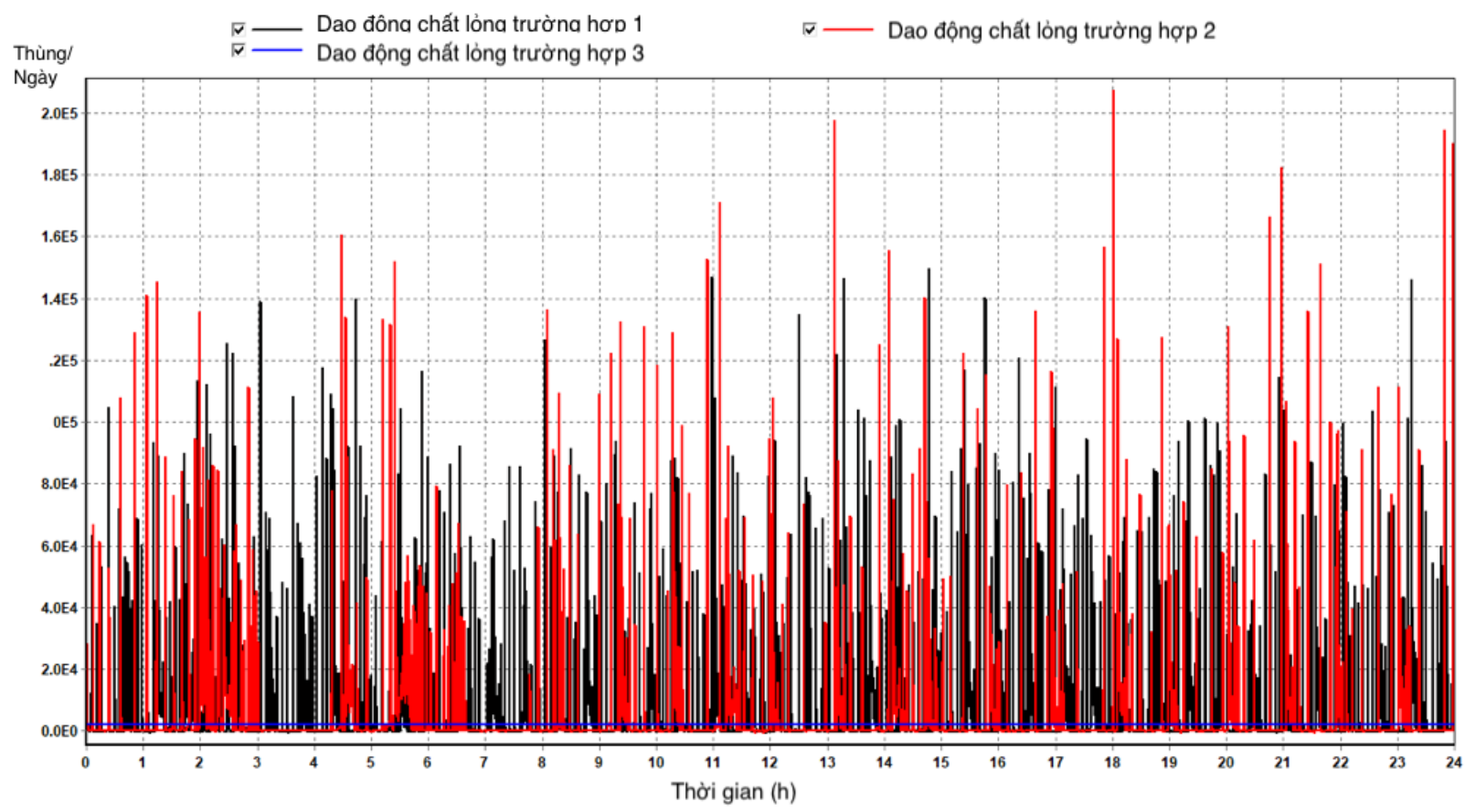

Hình 4. Trạng thái ổn định của chất lỏng trong thòi gian 12 giò̀ tại FPSO Ruby-II.

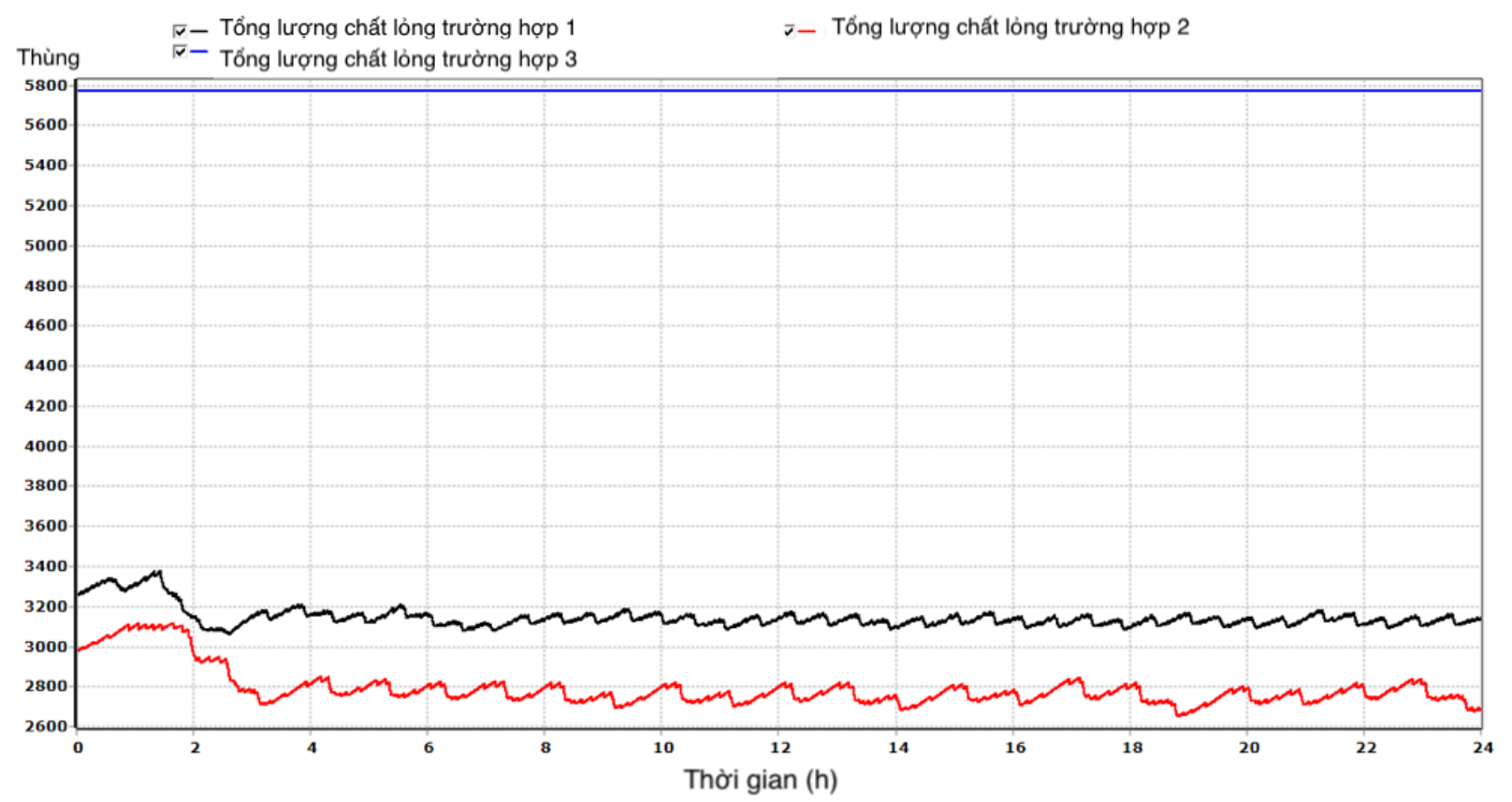

Hình 5. Tông lương chất lỏng trong đường ống trong thòi gian 12 giò. 
च- Lương chất lỏng tồn đọng trường hợp 1

『- Lượng chất lòng tồn đọng trường hợp 2

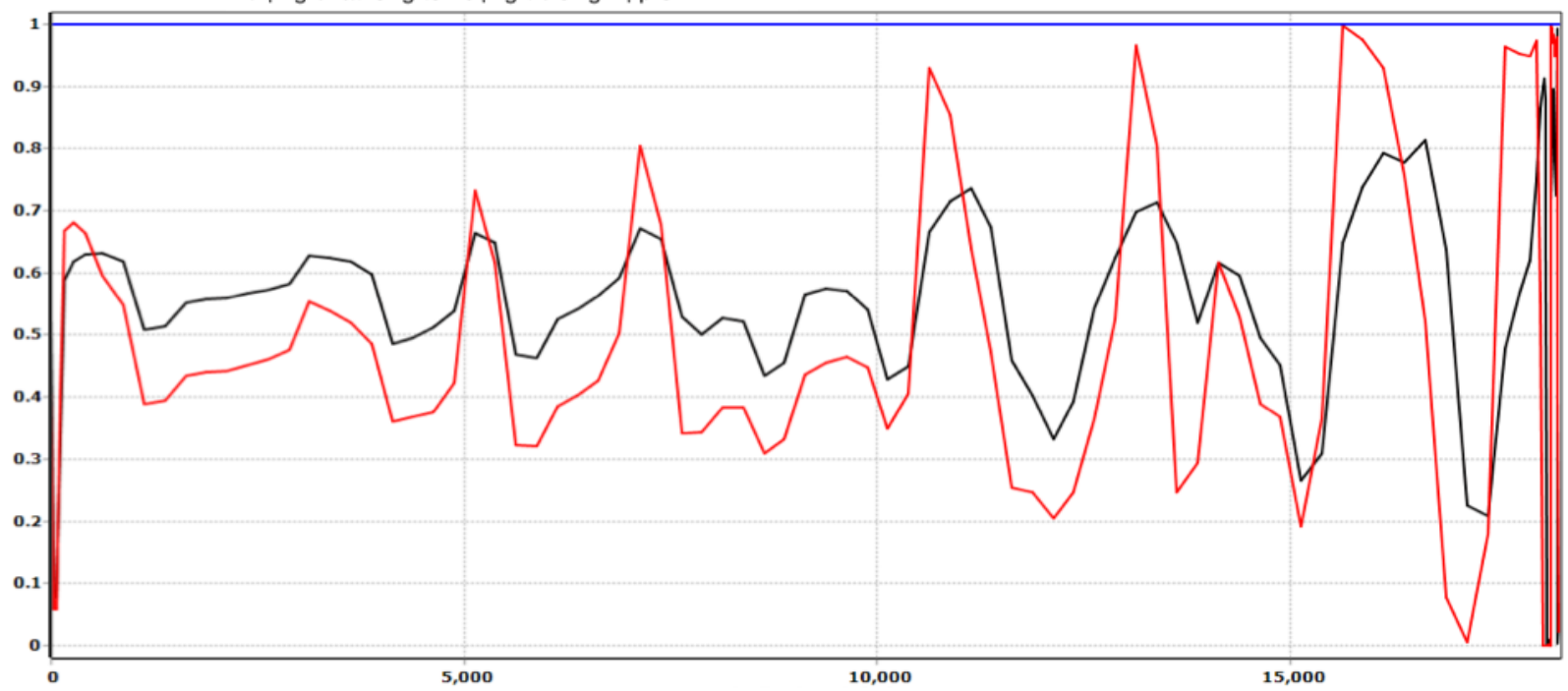

Hình 6. Chất lỏng tồn đọng dọc theo đường ống cho các trường hợp nghiên cúu.

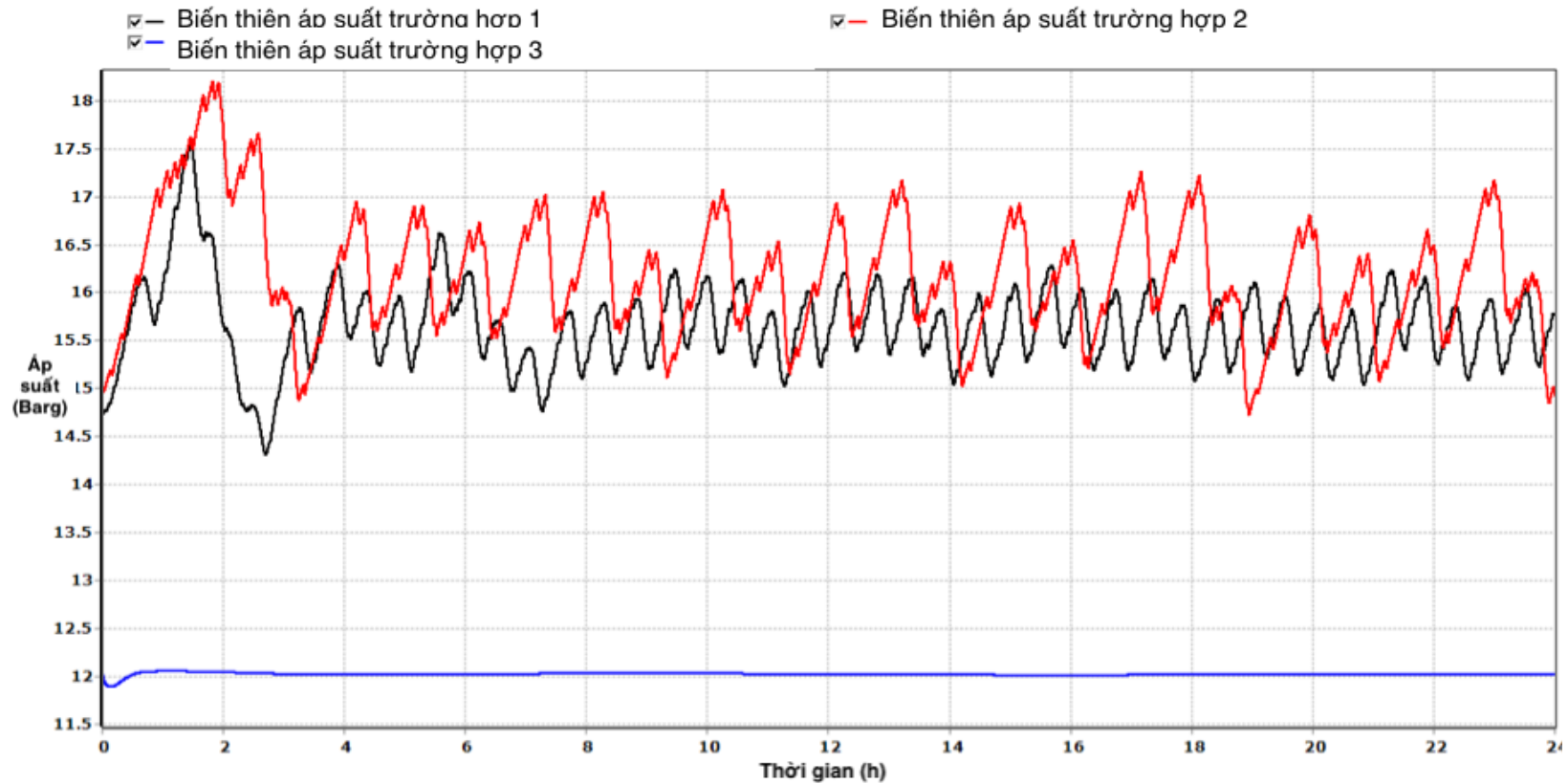

Hình 7. Biến thiên áp suất tại ống đứng lên tàu FPSO cho 3 trường hợp nghiên cứu trong 24 giò̀.

- Xác định độ biến thiên nhiệt độ

Đối với trạng thái biến thiên nhiệt độ của đường ống trong 3 trường hợp nghiên cứu được thể hiện trong Hình 8. Kết quả tính toán mô phỏng cho thấy, kể từ vị trí nửa cuối của tuyến ống, nhiệt độ của chất lỏng đối với các trường hợp nghiên cứu là $22^{\circ} \mathrm{C}$. Giá trị này gần bằng với nhiệt độ đáy biển, do đó sản phẩm khai thác của Diamond được vận chuyển dưới nhiệt độ đông đặc của nó $\left(36^{\circ} \mathrm{C}\right)$.

\section{Hiệu quả của việc sử dụng hóa phẩm giảm nhiệt độ đông đặc của dầu}

Qua các phân tích ở trên cho thấy, khả năng xảy ra hiện tượng đông đặc của dầu trong quá trình vận chuyển là rất cao. Vì vậy, cần phải có giải pháp xử lý phù hợp để hạn chế vấn đề này. Căn cứ vào điều kiện thực tế của mỏ, việc sử dụng hóa phẩm là giải pháp hiệu quả để làm giảm nhiệt độ đông đặc của dầu. 
Nguyễn Văn Thịnh và nnk/Tạp chí Khoa học Kỹ thuật Mỏ - Địa chất 62 (2), 65 - 78

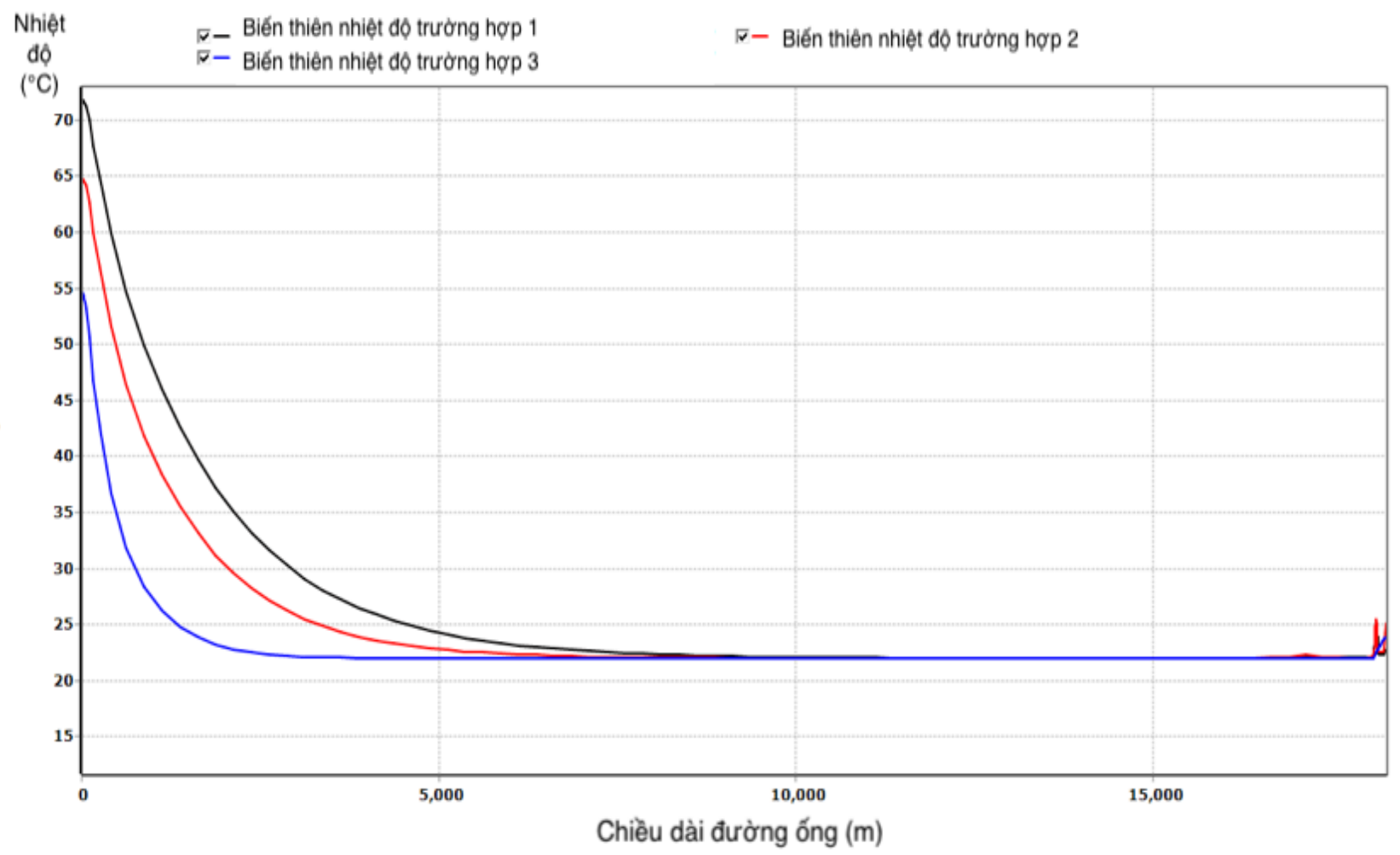

Hình 8. Biến thiên nhiệt độ dọc theo đường ống cho 3 trường hợp nghiên cúu.

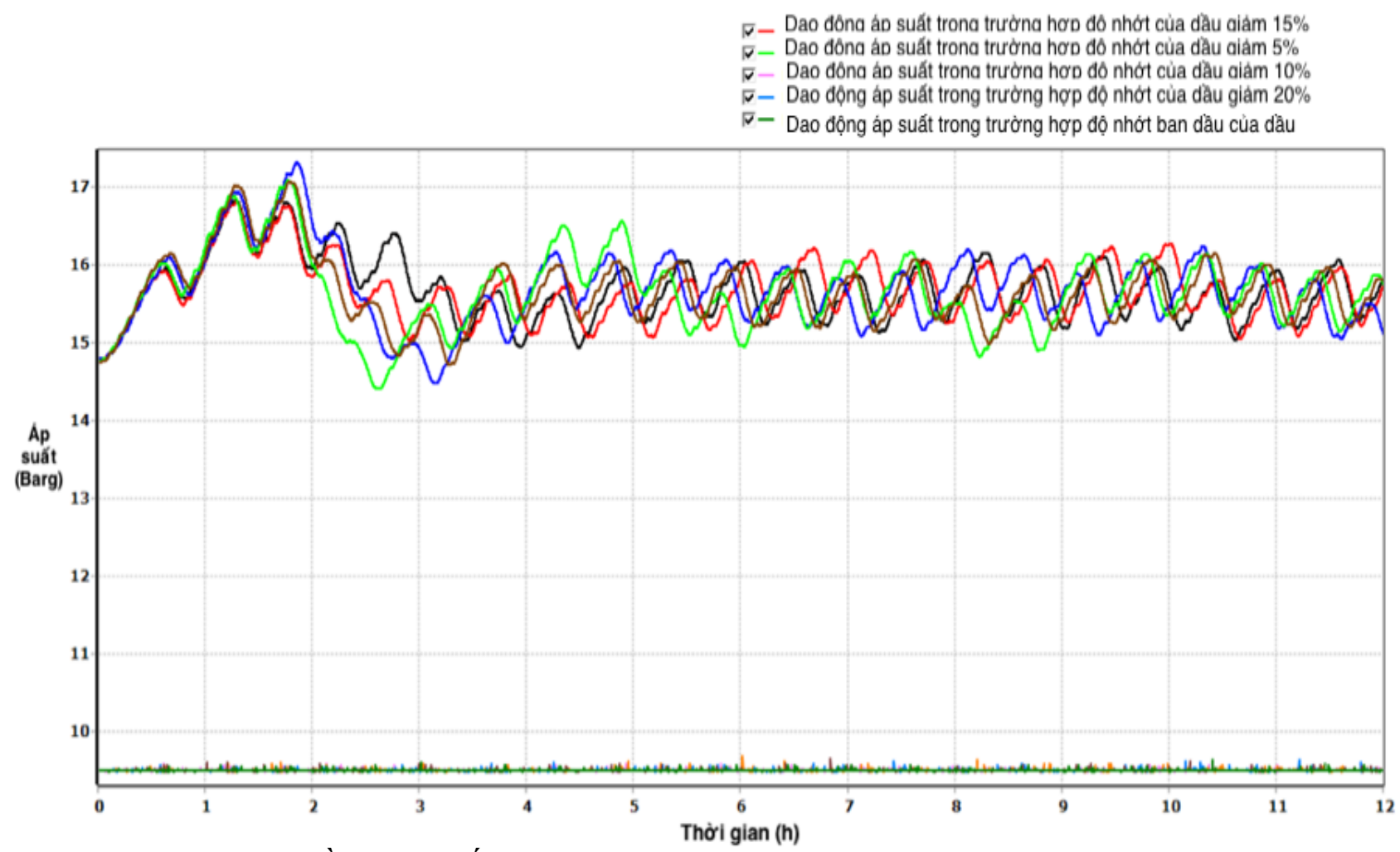

Hình 9. Đồ thị áp suất trong truờng hợp 1 với với các độ nhớt khác nhau. 


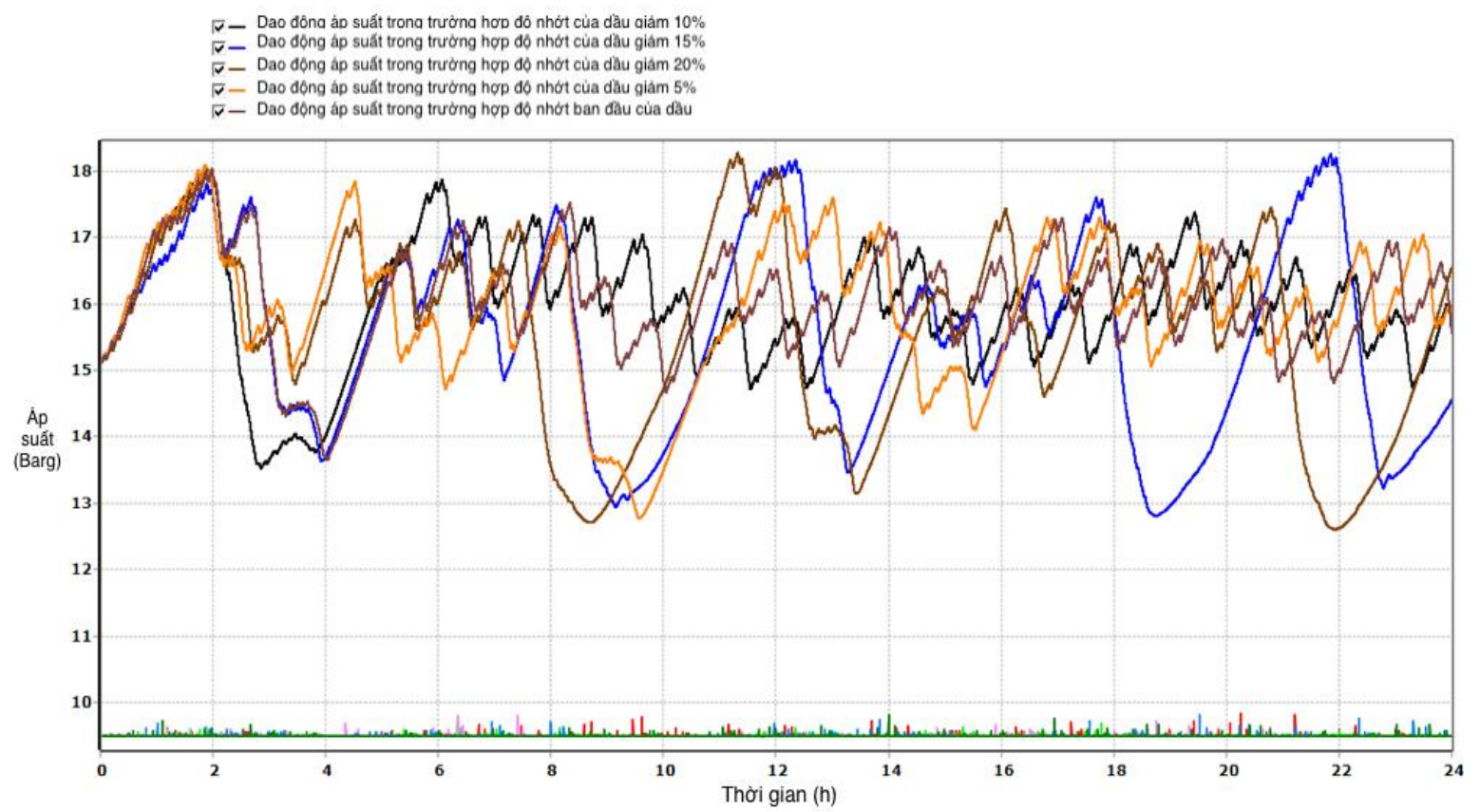

Hình 10. Đồ thị áp trong truờng hợp 2 với các độ nhớt khác nhau.

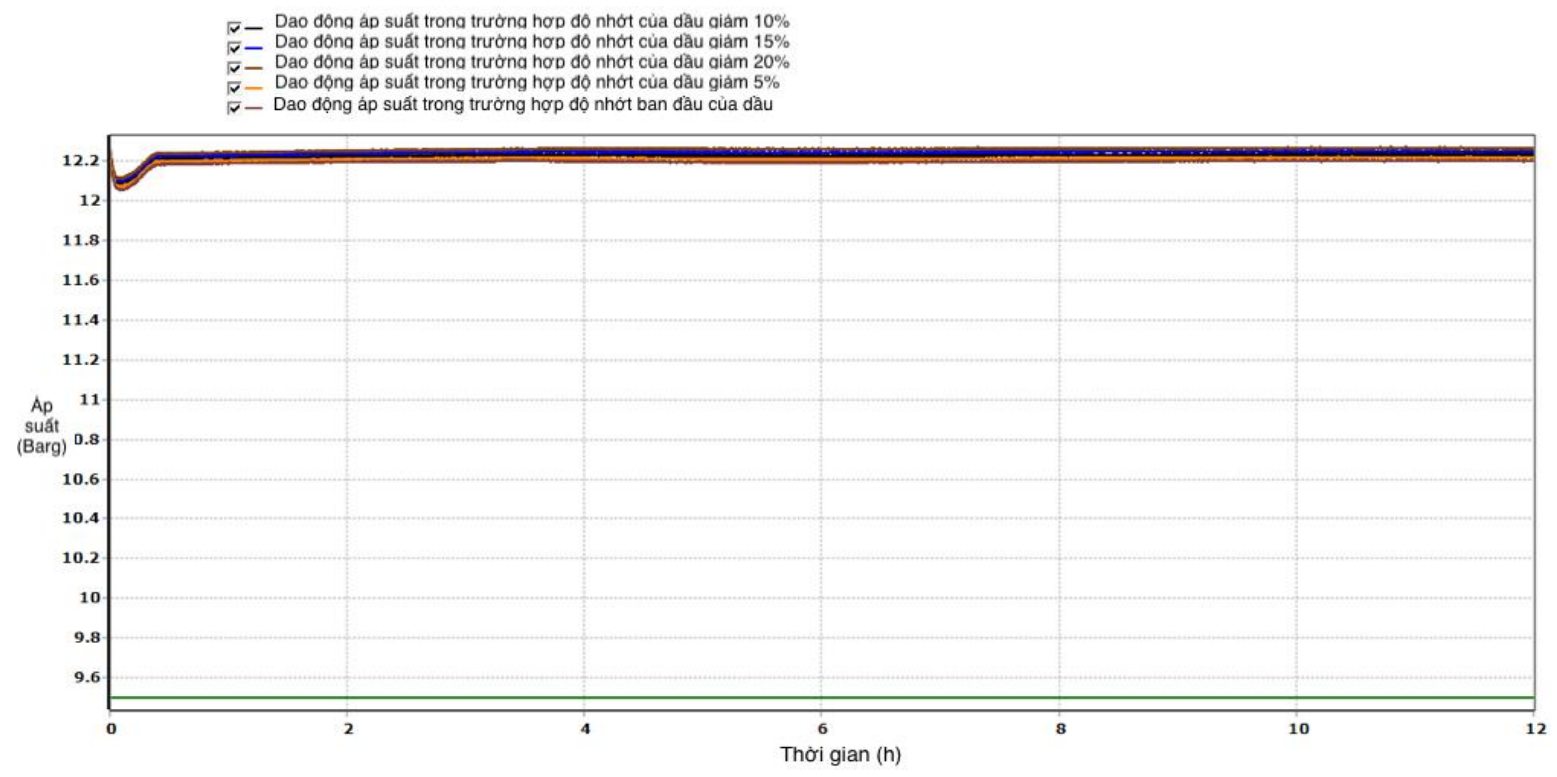

Hình 11. Đồ thị áp suất trong truờng hợp 3 vơi các độ nhớt khác nhau.

Các phân tích về độ nhạy và hiệu quả của hóa phẩm giảm nhiệt độ đông đặc (PPD) cho thấy, thông thường độ nhớt của dầu giảm trong khoảng $5 \%, 10 \%, 15 \%, 20 \%$ được so sánh với ảnh hưởng PPD bởi các kết quả trong phòng thí nghiệm. Kết quả nghiên cứu được chỉ ra trong các Hình 9, 10, 11 cho 3 kịch bản nghiên cứu. Việc tăng độ nhớt của dầu dần đến tăng khoảng biến động của áp suất ở đoạn ống mềm DMDP - A và có thể ảnh hưởng đến sự ổn định của điều kiện vận hành.

Đối với trường hợp 1 (năm 2020) áp suất ở đoạn ống mềm DMDP - $\mathrm{A}$ ổn định với sự thay đổi độ nhớt trong khoảng $5 \%, 10 \%, 15 \%$ và $20 \%$. Đối với trường hợp 2 (năm 2023) khi giảm khai thác dầu và GOR tăng, áp suất ở đoạn ống mềm DMDP - A không ổn định, khi đó độ nhớt dầu tăng. Tuy nhiên, theo mô phỏng cho thấy áp suất ở DMDP - 
A vẫn trong khoảng $12 \div 18$ bar. Đối với trường hợp 3 (năm 2026) khi vận chuyển không có khí, lượng dầu khai thác thấp và hàm lượng nước cao. Sự thay đổi độ nhớt không ảnh hưởng đến giá trị áp suất ở đoạn ống mềm DMDP - A.

\section{Thảo luận kết quả nghiên cứu}

\subsection{Trường hợp dùng đường ống}

Trường hợp dừng đường ống trong vòng 24 giờ. Van chặn ở FPSO Ruby-II giả định đóng trong 1 phút và đầu giếng Topaz giảm khai thác từ $100 \%$ xuống $0 \%$ trong 1 phút. Chất lỏng được tháo đi và gom lại ở các điểm thấp hơn. Lượng chất lỏng tích tụ sau 24 giờ dừng đường ống cho 3 trường hợp nghiên cứu được thể hiện trong Hình 12.

Lượng chất lỏng tích tụ trong hệ thống trong trường hợp dừng đường ống đối với 3 trường hợp nghiên cứu được trình bày trong Bảng 8 . Đối với đường ống không được bọc cách nhiệt, nhiệt độ của chất lỏng giảm xuống rất nhanh (Hình 13). Sau
5 giờ dừng đường ống nhiệt độ giảm tiệm cận với nhiệt độ môi trường.

\subsection{Khởi động lại đường ống}

Áp suất khởi động đường ống được xác định theo công thức:

$$
\Delta \mathrm{P} \_\mathrm{s}=\left(4 \mathrm{~L} \sigma \_\mathrm{s}\right) / \mathrm{D}
$$

Trong đó: $\Delta \mathrm{P}_{-} \mathrm{s}-$ khoảng tăng áp suất khởi động $(\mathrm{Pa}) ; \mathrm{L}$ - chiều dài đường ống $(\mathrm{m})$; $\sigma_{-} \mathrm{s}$ - ứng suất chảy của vật liệu $(\mathrm{Pa})$; $\mathrm{D}$ - đường kính trong của ống $(\mathrm{m})$.

Kết quả tính toán về áp suất khởi động đường ống được trình bày trong Bảng 9 và 10 . Kết quả nghiên cứu cho thấy, trong thời gian dừng đường ống sau 24 giờ, áp suất khởi động của trường hợp 1 và 3 cao hơn trường hợp 2 (năm 2023). Áp suất khởi động cho trường hợp 3 với sản phẩm vận chuyển không có khí, cao hơn đáng kể, do lượng dầu tồn đọng trong đường ống lớn.

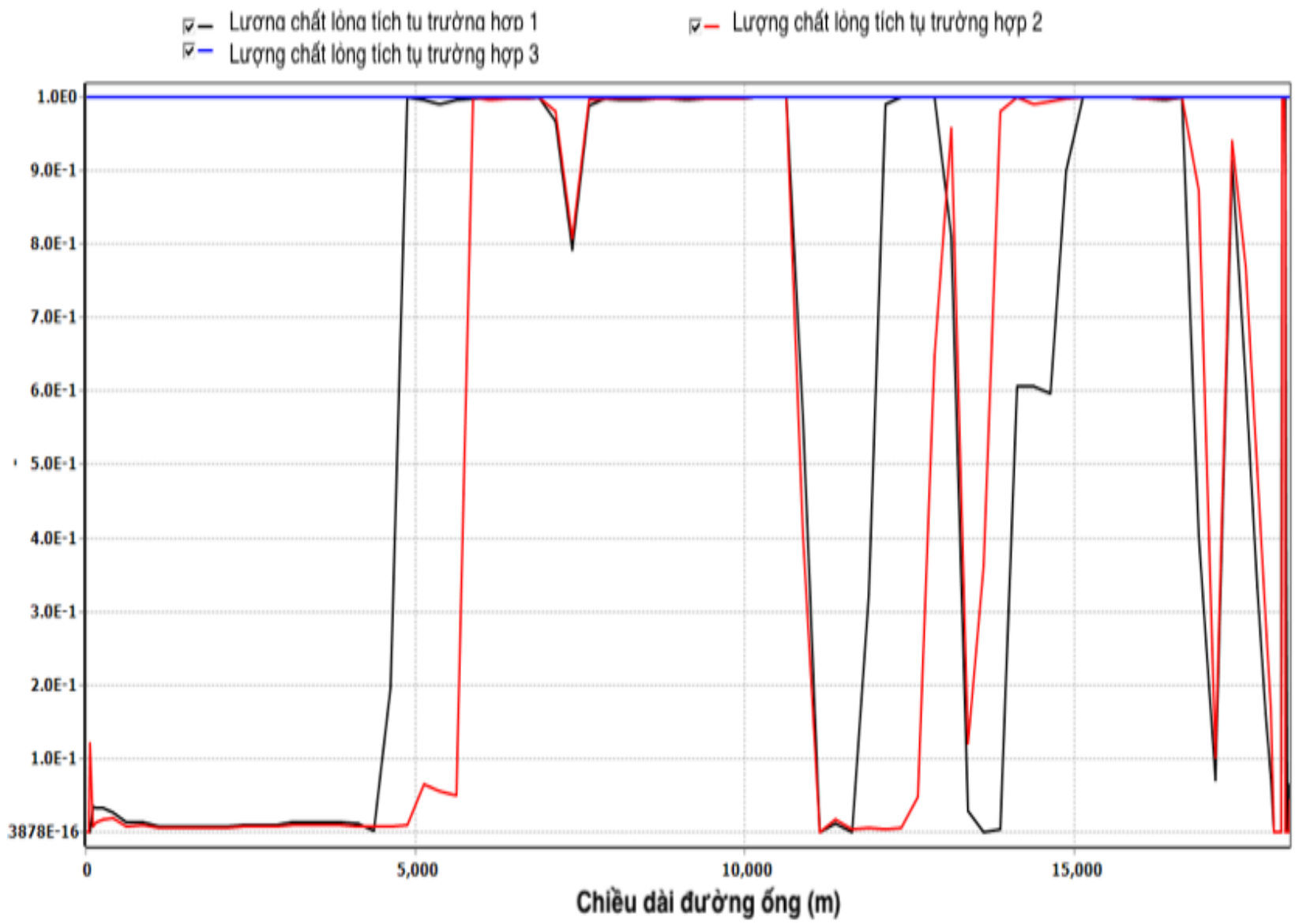

Hình 12. Đồ thị tích tụ chất lỏng sau 24 giờ dù̀ng đường ống cho 3 trường hợp. 


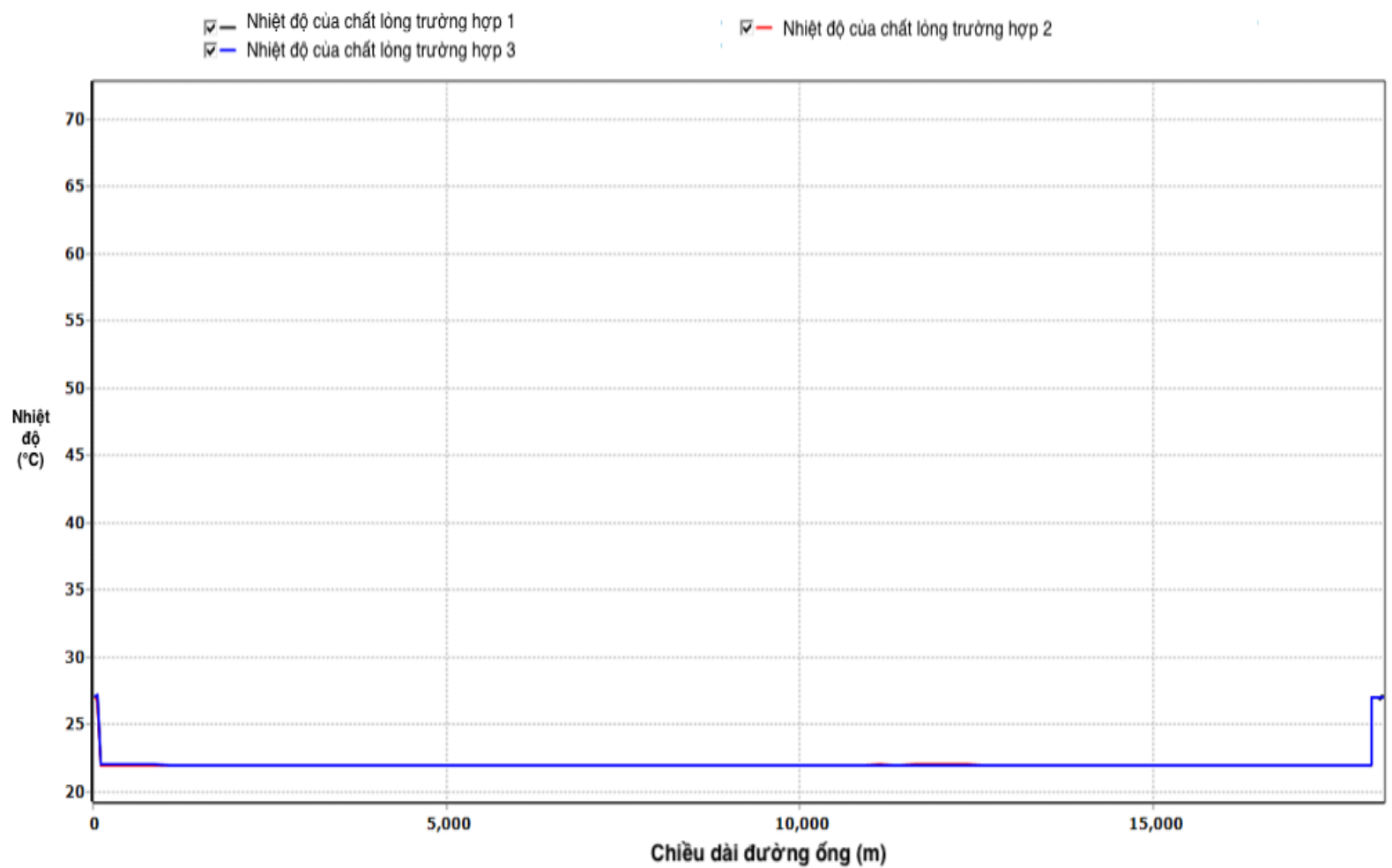

Hình 13. Đồ thị nhiệt độ của chất lỏng sau 24 giò dùng đường ống.

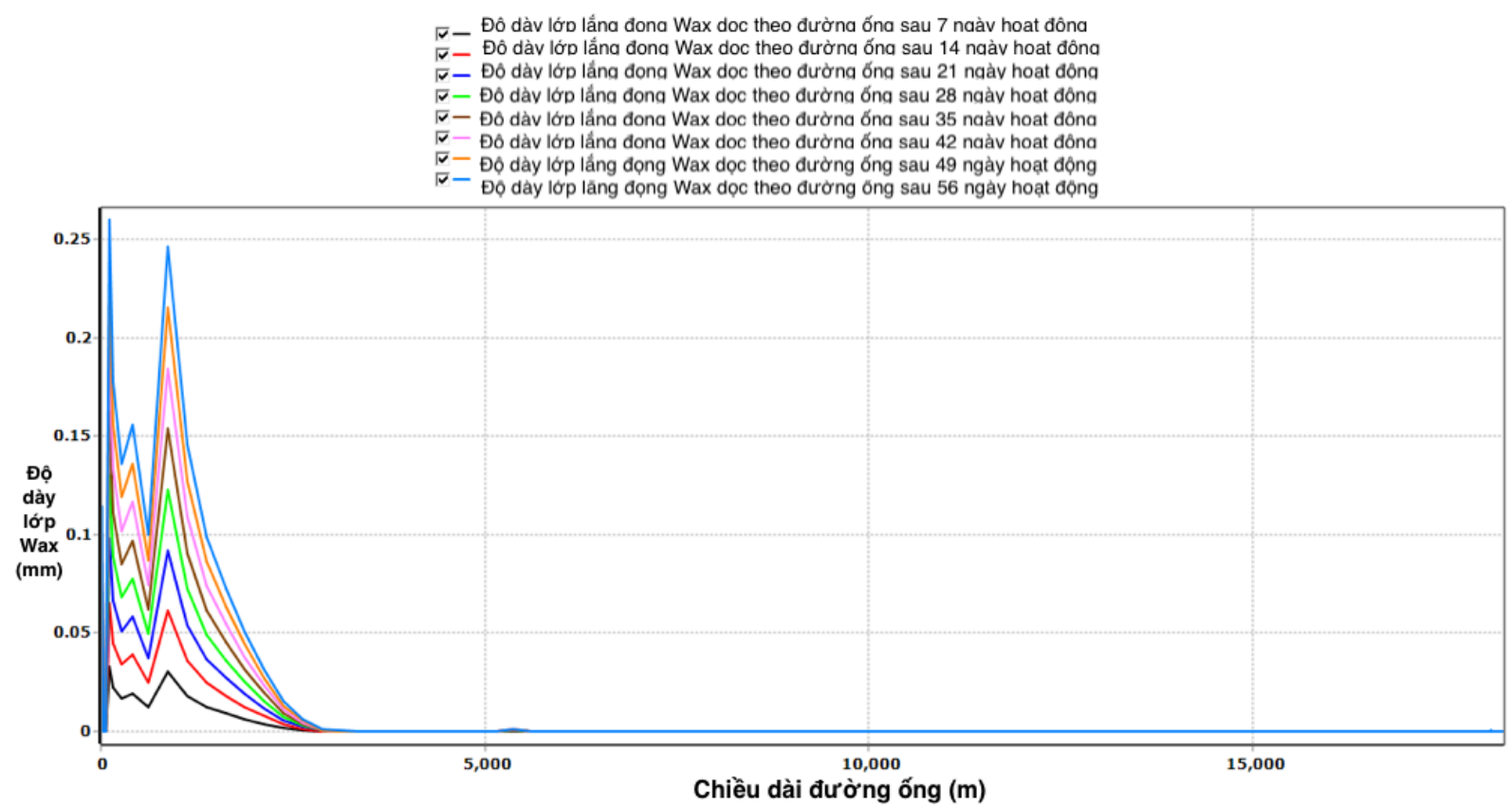

Hình 14. Độ dày lớp wax dọc theo đường ống sau 7, 14, 21, 28, 35, 42, 49 và 56 ngày hoạt động.

Bảng 8. Thể tích chất lỏng và dầu trong đường ống.

\begin{tabular}{|c|c|c|c|}
\hline Trường hợp & Năm & Chất lỏng (Thùng) & Dầu (Thùng) \\
\hline 1 & 2020 & 3318 & 990 \\
\hline 2 & 2023 & 2987 & 572 \\
\hline 3 & 2026 & 5774 & 1697 \\
\hline
\end{tabular}


Bảng 9. Áp suất khởi động của đường ống trong trường hợ không sử dụng PPD.

\begin{tabular}{|c|c|c|c|c|c|c|}
\hline \multirow{2}{*}{ Thời gian } & \multicolumn{2}{|c|}{ TH 1 (năm 2020) } & \multicolumn{2}{c|}{ TH 2 (năm 2023) } & \multicolumn{2}{c|}{ TH 3 (năm 2026) } \\
\cline { 2 - 7 } & $\begin{array}{c}\text { Chiều } \\
\text { dài, } m\end{array}$ & $\begin{array}{c}\text { Áp suất khởi } \\
\text { động, bar }\end{array}$ & $\begin{array}{c}\text { Chiều dài, } \\
\mathrm{m}\end{array}$ & $\begin{array}{c}\text { Áp suất khởi } \\
\text { động, bar }\end{array}$ & $\begin{array}{c}\text { Chiều } \\
\text { dài, } \mathrm{m}\end{array}$ & $\begin{array}{c}\text { Áp suất khơoi } \\
\text { động, bar }\end{array}$ \\
\hline 6 & 3149 & 35 & 1814 & 20 & 4862 & 54 \\
\hline 12 & 3163 & 39 & 1810 & 22 & 4995 & 61 \\
\hline 24 & 3152 & 46 & 1815 & 26 & 5331 & 77 \\
\hline
\end{tabular}

Bảng 10. Áp suất khởi động của đường ống trong trường hợp có sử dụng PPD.

\begin{tabular}{|c|c|c|c|c|c|c|}
\hline \multirow{2}{*}{ Thời gian } & \multicolumn{2}{|c|}{ TH 1 (năm 2020) } & \multicolumn{2}{c|}{ TH 2 (năm 2023) } & \multicolumn{2}{c|}{ TH 3 (năm 2026) } \\
\cline { 2 - 7 } & $\begin{array}{c}\text { Chiều } \\
\text { dài, } m\end{array}$ & $\begin{array}{c}\text { Áp suất khởi } \\
\text { động, bar }\end{array}$ & $\begin{array}{c}\text { Chiều dài, } \\
\mathrm{m}\end{array}$ & $\begin{array}{c}\text { Áp suất khởi } \\
\text { động, bar }\end{array}$ & $\begin{array}{c}\text { Chiều } \\
\text { dài, } m\end{array}$ & $\begin{array}{c}\text { Áp suất khời } \\
\text { động, bar }\end{array}$ \\
\hline 6 & 3149 & 22,4 & 1814 & 12,9 & 4862 & 34,5 \\
\hline 12 & 3163 & 24,6 & 1810 & 14,1 & 4995 & 38,8 \\
\hline 24 & 3152 & 28,7 & 1815 & 16,5 & 5331 & 48,5 \\
\hline
\end{tabular}

\subsection{Kiểm soát lắng đọng wax}

Kết quả phân tích sự hình thành wax cho thấy tốc độ hình thành lớp lắng đọng này ở mức độ thấp. Sau 56 ngày hoạt động, độ dày lớp wax lắng đọng đạt mức $0,25 \mathrm{~mm}$ (Hình 14). Đồng thời sự hình thành của wax trên đoạn ống đứng dốc đạt giá trị lớn nhất. Tổng lượng wax hình thành trong đường ống được thể hiện ở Bảng 11. Sự hình thành các lớp lắng đọng wax trên thành ống gây ra những phức tạp cho quá trình vận chuyển sản phẩm.

Bảng 11. Tổng lượng wax hình thành trong đường ống.

\begin{tabular}{|c|c|c|}
\hline Ngày & Thùng & Khối lương $(\mathrm{kg})$ \\
\hline 7 & 0,17 & 12,81 \\
\hline 14 & 0,33 & 25,62 \\
\hline 21 & 0,50 & 38,45 \\
\hline 28 & 0,66 & 51,29 \\
\hline 35 & 0,83 & 64,14 \\
\hline 42 & 1,00 & 77,02 \\
\hline 49 & 1,16 & 89,93 \\
\hline 56 & 1,33 & 102,85 \\
\hline
\end{tabular}

Để loại bỏ lớp lắng đọng này, cần tiến hành nạo vét đường ống từ giàn Diamond tới FPSO Ruby-II bằng kỹ thuật phóng Pig làm sạch đường ống (Pigging). Loại pig được sử dụng ở đây là Foam Pig, với tần suất 1 tháng 1 lần. Trong trường hợp này, một Pig được phóng ở điểm đầu của đoạn ống đứng trên giàn Diamond và điểm thu hồi Pig là ở FPSO Ryby-II.

\section{Kết luận}

Áp suất vận chuyển dao động trong khoảng $13 \div 18$ bar với các trường hợp nghiên cứu. Chất lỏng được làm mát đến nhiệt độ đáy biển và được vận chuyển dưới nhiệt độ đông đặc trên hầu hết đường ống. Thời gian để chất lỏng được làm mát đến nhiệt độ đáy biển mất khoảng 5 giờ kể từ khi Shut - down. Tỷ lệ hình thành wax ở điều kiện ổn định bình thường là tương đối thấp. Wax ở phần dưới ở đoạn cuối của ống đứng dốc xuống tương đối nhiều do đây là nơi mà nhiệt độ chất lỏng bị làm mát đến khoảng nhiệt dễ tạo thành wax. Sau 56 ngày hoạt động, độ dày lớn nhất của wax là khoảng $0,25 \mathrm{~mm}$. Kết quả mô phỏng cũng cho thấy, độ dày của lớp paraffin được tạo ra là tương đối nhỏ. Tuy nhiên, do nhiệt độ dầu vận chuyển thấp hơn nhiệt độ đông đặc, dẫn đến một lớp wax sẽ hình thành và bám trên bề mặt của đường ống. Khi độ dày trung bình của lớp wax xuất hiện trong thành đường ống đạt khoảng $5 \mathrm{~mm}$, sẽ tiến hành sử dụng các phương pháp nạo vét. Đây là cách loại bỏ paraffin hiệu quả nhất. Tần suất loại bỏ hợp lý là 1 tháng lần.

\section{Đóng góp của tác giả}

Nguyễn Văn Thịnh: xây dựng ý tưởng, bố cục bài báo, phân tích kết quả nghiên cứu, biên tập và hiệu đính toàn bộ bài báo; Nguyễn Đức Chính: chạy mô hình và xuất kết quả tính toán; Triệu Hùng Trường: cung cấp thông tin và ý kiến bổ sung cho bài báo. 


\section{Tài liệu tham khảo}

Từ Thành Nghĩa, Phạm Bá Hiển, Phạm Xuân Sơn, Tống Cảng Sơn, Nguyễn Hoài Vũ, Ngô Thường San, Nguyễn Văn Minh, Nguyễn Thúc Kháng. (2015). Những khó khăn thách thức của Vietsovpetro trong vận chuyển dầu nhiều paraffin bằng đường ống ngầm ngoài khơi. Tạp chí Dầu khí số, 5/2015, 20 - 25.

Phung Dinh Thuc, Tong Canh Son, Le Dinh Hoe, V.P. Vugovskoi. (2003). The problem in Transportation of High Waxy Crude oils Through Submarine Pipelines at JV Vietsovpetro Oil Fields, Offshore Vietnam. Journal of Canadian Petroleum Technology, Solution for Production Optimization, Canada, $42,15-18$.

Hyun Su Lee. (2008). Computational and rheological study of wax deposition and gelation in subsea pipeline. The University of Michigan.

PVEP. (2019).Analysis report - Crude Oil Samples.

PVEP. (2018). Composition analysis report - Gas Samples

Ove Bratland. (2013). Pipe Flow - Multi - phase Flow Assurance.

Aiyejna, A., Chakrabarti, D.P., Pilgrim, A., Sastry, M. K. S. (2011). Wax formation in Oil Pipelines: A critical Review. International Journal of Multiphase Flow, 37, 671 - 694.

Burger, E.D., Perkins, T. K, Striegler, J. H. (1981). Studies of Wax Deposition in the Trans Alaska Pipeline. Journal of Petroleum Technology, 1075 - 1086. 